\section{Fecal Shedding of SARS CoV-2: Implications for Disease Spread and Quarantine}

COVID-19 has already spread to more than 200 countries affecting 1,210,956 humans and resulting in 67594 deaths worldwide [1]. It predominantly affects adults whereas children constitute about $1-5 \%$ of all confirmed cases [2]. Similar to adults, cough (48.5\%) and fever $(41.5 \%)$ are the most common manifestation in children [2]. However, a significant proportion (8-30\%) of children have presented with gastrointestinal (GIT) symptoms too $[2,3]$, suggesting the predilection of COVID-19 for the angiotensin-converting enzyme II receptor of GIT [4]. The overall incidence of GIT symptoms might be underreported as screening is solely based on respiratory symptoms as of now.

The above observations are well supported by recent studies. Wu, et al. [5] reported that 55\% of patients' fecal samples were positive for SARS CoV-2 RNA by real-time RT-PCR, and it remained positive for 27.9 days. Importantly, the fecal sample remained positive longer than the respiratory samples [5]. In another series of 10 children, the rectal swab was positive in seven patients, and the viral RNA was detected in stool well after the respiratory tract sample turned negative [3]. These findings suggest that viral shedding from the gastrointestinal tract persists much beyond ( $\sim 2$ weeks) the respiratory system. This is thought to be due to low cycle threshold $(\mathrm{Ct})$ or high viral load in stool sample as compared to nasopharyngeal swab [3].Till now the infectivity of the fecal shedding is not proven, and there are chances of fecal viral genomic material shedding without any infective potential. However, this 'no evidence of infectivity' shall not be taken as 'evidence of non-infectivity'. Considering mild course of COVID-19 in children, these findings may not have much relevance for themselves but their probable potential carrier status will have strong implications over the containment strategies. Therefore, it will be wiser to follow toilet hygiene along with respiratory hygiene and etiquette.

Most current guidelines recommend discharging COVID-19 patients when they turn asymptomatic with two negative consecutive oropharyngeal swab RT-PCR done at least one day apart. However, the recent reports of persistent fecal shedding even up to three weeks after negative oropharyngeal swabs are of concern $[3,5]$. We understand that in current scenario, amidst a limited supply of kits, testing for fecal shedding may not be wise.
But, ignorance to their probable carrier status may continue the chain of transmission. Also, there are instances where patients were discharged after two consecutively negative swabs and later became symptomatic and were re-admitted. On re-admission, the repeat swab report came out positive [3]. However, these instances are mostly related to false negative results (either due to poor sampling technique or low sensitivity of the kit) of the earlier tests. The more robust animal studies suggest that the reinfection with SARS-CoV-2 does not occur [6]. However, to be on the safer side, shouldn't we go for more stringent steps and keep them in home-isolation for two more weeks after negative nasopharyngeal swab?

Funding: None; Competing interest: None stated.

Published online: April 11, 2020; PII: S097475591600160

JiTENDRA MEENA ${ }^{1}$ AND JOGENDER KUMAR ${ }^{2 *}$

Departments of Pediatrics, ${ }^{1}$ All India Institute of Medical Sciences, New Delhi, and ${ }^{2}$ Post Graduate Institute of Medical Education and Research, Chandigarh; India. Jogendrayadv@gmail.com.

\section{REFERENCES}

1. World Health Organization. Coronavirus disease 2019 (COVID-19) Situation Report - 77. Available from https:// www.who.int/docs/default-source/coronaviruse/situationreports/20200406-sitrep-77-covid-19.pdf?sfvrsn = 21d1e632_2. Accessed on April 7, 2020.

2. LudvigssonJF. Systematic review of COVID-19 in children shows milder cases and a better prognosis than adults. ActaPaediatr.2020. Available from: https:// onlinelibrary. wiley.com/doi/abs/10.1111/apa.15270. Accessed on April 4, 2020

3. Xu Y, Li X, Zhu B, Liang H, Fang C, Gong Y, et al. Characteristics of pediatric SARS-CoV-2 infection and potential evidence for persistent fecal viral shedding. Nat Med. 2020.Available from: https://www.nature.com/ articles/s41591-020-0817-4.pdf.Accessed on April 9, 2020.

4. Ma X, Su L, Zhang Y, Zhang X, Gai Z, Zhang Z. Do children need a longer time to shed SARS-CoV-2 in stool than adults?J Microbiol Immunol Infect. 2020 Mar 19. Available from:https://www.sciencedirect.com/science/ article/pii/S1684118220300700? via\%3Di hub.Accessed on April 9, 2020.

5. Wu Y, Guo C, Tang L, Hong Z, Zhou J, Dong X, et al. Prolonged presence of SARS-CoV-2 viral RNA in faecal samples. Lancet GastroenterolHepatol. 2020. Available from:https://www.thelancet.com/journals/langas/article/ PIIS2468-1253(20)30083-2/fulltext. Accessed on April 4, 2020.

6. Bao L, Deng W, Gao H, Xiao C, Liu J, Xue J, et al. Reinfection could not occur in SARS-CoV-2 infected rhesus macaques [Internet]. Microbiology. 2020. Available from: http://biorxiv.org/lookup/doi/10.1101/2020.03.13.990226. Accessed on April 9, 2020. 